\title{
Editorial
}

\section{World-Wide Challenges and Perspectives for Handling HIV/Mycobacterium tuberculosis Co-Infections}

\author{
Martina Sester ${ }^{*}, 1$, Claudia Giehl², Beate Kampmann ${ }^{3}$ and Andreas Meyerhans ${ }^{*}, 4$ \\ ${ }^{I}$ Department of Transplant and Infection Immunology, Institute of Virology, University of the Saarland, Homburg, \\ Germany \\ ${ }^{2}$ European Research and Project Office GmbH - Eurice, Saarbrücken, Germany \\ ${ }^{3}$ Academic Department of Paediatrics, Imperial College London, UK \\ ${ }^{4}$ ICREA Infection Biology Laboratory, Department of Experimental and Health Sciences, University Pompeu Fabra, \\ Barcelona, Spain
}

Keywords: HIV/M. tuberculosis co-infection, research priorities, EUCO-Net.

This special issue of the Open Journal of Infectious Diseases is dedicated to the particular threat caused by the coinfection of the Human Immunodeficiency Virus (HIV) and Mycobacterium tuberculosis (MTB). These pathogens induce the acquired immunodeficiency syndrome (AIDS) and tuberculosis (TB), two major communicable diseases with severe public health impact worldwide. Estimates of the World Health Organisation (WHO) and UNAIDS reveal a frightening prevalence: around 33 million individuals are infected with HIV and one third of the world's population carries MTB. While both infections are representing global public health problems in their own right, their combination is particularly threatening due to considerable mutual interactions: In HIV-positive individuals infected by MTB, the risk to develop active TB is 21-37 times higher than that of the HIV-negative population [1]. As a consequence, TB has become the leading cause of mortality for people living with HIV/AIDS, even in regions where highly active antiretroviral therapy (ART) has been implemented, and HIV is the most potent force driving the TB epidemic in countries with a high prevalence of HIV infection. Currently, this "cursed duet" of AIDS/TB is exerting its detrimental effects in settings where HIV and MTB prevalence is highest (such as in Sub-Saharan Africa, India, Russia or Latin America) and where multidrug- (MDR) and extensively drug resistant TB (XDR-TB) are present [2-4].

In this context, the European Union financed a multi-national support action named "EUCO-Net" (http://www.euco-net.eu)

*Address correspondence to these authors at the Department of Transplant and Infection Immunology, Institute of Virology, Saarland University, 66421 Homburg, Germany; Tel: 0049-6841-16-23557; Fax: 0049-6841-1621347; E-mail: martina.sester@uks.eu or Infection Biology Laboratory, Department of Experimental and Health Sciences, University Pompeu Fabra, Barcelona, Spain; Tel: 0034-933-160-831;

E-mail: andreas.meyerhans@upf.edu bringing together over 60 experts from Europe and those regions mainly affected by the two diseases, namely Russia, India, sub-Saharan Africa and Latin America. The aim of the EUCO-Net project was to provide a platform for scientists with complementary expertise and background to form new consortia for future projects addressing the global threat of AIDS, TB, and their deadly combination. The group worked together to identify priority areas for future research in order to prepare future community research and technological development policies. Together, the EUCO-Net experts analyzed and discussed the situation of AIDS, TB, and HIV/MTB co-infection on a national level and subsequently proposed priority areas for trans-national research and concerted actions in a jointly elaborated AIDS/TB Roadmap.

This special issue of the Open Journal of Infectious Diseases provides an overview of the HIV/MTB epidemiology and disease management in the different partner countries, and identifies global research priorities in order to boost international cooperation between leading HIV and TB experts from Europe and those countries mainly affected by the two diseases - Africa, India, Latin America, and Russia.

\section{REFERENCES}

[1] WHO. Global tuberculosis control: epidemiology, strategy, financing. Geneva: World Health Organisation 2009.

[2] Sester M, Giehl C, McNerney R, et al. Challenges and perspectives for improved management of HIV/Mycobacterium tuberculosis coinfection. Eur Respir J 2010; 36(6): 1242-7.

[3] Migliori GB, Loddenkemper R, Blasi F, Raviglione MC. 125 years after Robert Koch's discovery of the tubercle bacillus: the new XDR-TB threat. Is "science" enough to tackle the epidemic? Eur Respir J 2007; 29(3): 423-7.

[4] Sotgiu G, Ferrara G, Matteelli A, et al. Epidemiology and clinical management of XDR-TB: a systematic review by TBNET. Eur Respir J 2009; 33(4): 871-81.

(C) Sester et al.; Licensee Bentham Open.

This is an open access article licensed under the terms of the Creative Commons Attribution Non-Commercial License (http://creativecommons.org/licenses/ by-nc/3.0/) which permits unrestricted, non-commercial use, distribution and reproduction in any medium, provided the work is properly cited. 